\title{
Incidental extravascular findings in CT angiograms in patients post endovascular abdominal aortic aneurysm repair: clinical relevance and frequency
}

Permesh Singh Dhillon ${ }^{1,2,3^{*}+}$, Mohammad Waleed Butt ${ }^{1 \dagger}$, Graham Pollock ${ }^{1}$, James Kirk ${ }^{1}$, Peter Bungay ${ }^{1}$, Mario De Nunzio ${ }^{1}$ and Peter Thurley ${ }^{1}$

\begin{abstract}
Background: To evaluate the incidence and clinical relevance of extravascular incidental findings (EVIF), particularly malignancies, in planning and follow-up CT angiograms (CTA) of the abdominal aorta in patients who underwent endovascular aneurysm repair (EVAR) of abdominal aortic aneurysm. Retrospective study of 2203 planning and follow-up CTAs of 418 patients who underwent EVAR in a single tertiary centre between 2006 and 2015. CTA reports were scrutinized for EVIFs, which were classified according to clinical relevance, into (I) immediate, (II) potential and (III) no clinical relevance. Clinical follow-up and management were reviewed for significant findings. Follow-up CTAs of patients with incidental malignancies were re-reviewed by two consultant radiologists to evaluate if early missed malignant findings on previous CTAs were present.

Results: In total, 950 EVIFs were noted in 418 patients [31 females (7.4\%), 387 males (92.6\%); age range 63-93, mean age 79.0 years]. The number of patients with findings in each category were; Category I (115), Category II (165), Category III (304). Incidental malignant findings were reported in 51 patients (12.2\%), of which 27 were noted on the initial CTA (6.5\%) and 24 on follow-up CTAs (5.7\%). Of the 24 patients with malignancies on follow-up CTAs, 13 had early malignant findings missed or misinterpreted on previous CTAs, while 11 had no significant abnormality even on retrospective review.

Conclusion: A high number of significant EVIFs, particularly incidental malignancies, can be identified in follow-up CTAs of patients who undergo EVAR. Specific 'review areas' when reporting surveillance CTAs can be recommended based on the findings of our study.
\end{abstract}

Keywords: Abdominal aortic aneurysm (AAA), Endovascular aneurysm repair (EVAR), Incidental finding, CT angiogram

\footnotetext{
*Correspondence: permesh.dhillon@nhs.net

${ }^{\dagger}$ Permesh Singh Dhillon and Mohammad Waleed Butt contributed equally to this work.

${ }^{1}$ Clinical Radiology, Royal Derby Hospital, Derby Teaching Hospitals NHS

Foundation Trust, Derby, UK

${ }^{2}$ Radiological Sciences, University of Nottingham, Queen's Medical Centre,

Nottingham, UK

Full list of author information is available at the end of the article
} 


\section{Background}

Endovascular aneurysm repair (EVAR) has become the predominant treatment option for patients with abdominal aortic aneurysm (AAA) accounting for $78 \%$ of all elective repair in the United States in 2010 (Dua et al. 2014). In addition, recent large multi-centre randomised trials have demonstrated similar short-term outcomes between EVAR and open surgical repair for the treatment of ruptured AAA which may further increase endovascular management (Trial et al. 2009; Hoornweg et al. 2007).

Despite superior perioperative mortality outcomes and similar long-term survival compared to open surgical repair (Lederle et al. 2009; Greenhalgh et al. 2004), EVAR is beset by its higher rates of observed complications and need for secondary intervention (De Bruin et al. 2010; Hobo et al. 2006). Indications for re-intervention often include stent migration and endoleak with the associated risk of subsequent aneurysm rupture. Life-long surveillance is therefore recommended by multiple societies (Walker et al. 2010). Computed tomography angiography (CTA) remains the most widely used imaging modality for the purposes of pre-operative planning and surveillance due to its availability, high-throughput, reproducibility, contrast resolution and volumetric multi-planar reconstruction functionality. Although there is no consensus on surveillance frequency and modality, commonly used protocols traditionally incorporated arterial phase CTA imaging at 1, 6 and 12 month periods post-procedure and subsequent yearly follow-up (Hirsch et al. 2006). Several studies have demonstrated this can be done with similar sensitivity and specificity for endoleak detection as multiphase CT (Iezzi et al. 2006; Macari et al. 2006). Furthermore, some authors advocate the sole use of annual Doppler ultrasound for endoleak detection if no complications have been demonstrated on CTA at 12 months post-procedure (Chaer et al. 2009; Sternbergh 3rd et al. 2008).

Incidental findings are commonplace in clinical radiology and whilst they may lead to early significant diagnoses, over-diagnosis with unnecessary procedural or imaging work up and psychological distress to patients can also occur. Extravascular structures are readily depicted on CTA and previous studies demonstrated the prevalence of clinically significant incidental findings to be in the range of 5.6 and $12 \%$ (Katz et al. 1999; McDougal et al. 2006). Interestingly, higher rates of detection were shown in more recent studies which focussed on lower limb run off CTA with figures as high as $27 \%$ in patients presenting with acute limb ischaemia (Preuss et al. 2015). Therefore, our objectives were to primarily evaluate the frequency and clinical relevance of extravascular incidental findings (EVIF) in the post EVAR patient sub-set who undergo CTA and secondarily to assess reporting accuracy by retrospectively scrutinising prior images for evidence of early disease in cases where malignant findings had been demonstrated.

\section{Methods \\ Patient population}

A retrospective review of 2203 planning and surveillance CTAs of 418 patients who underwent EVAR (elective and emergency) in a single tertiary centre between 2006 and 2015 were included in this study. No IRB approval was required. No patients were excluded. Basic demographic data of age and gender was obtained. Each patient had at least a planning and surveillance CTA performed. Surveillance CTAs were obtained at 1, 6, and 12 monthly intervals unless follow up was converted to ultrasound imaging or if the patient had deceased.

\section{Image acquisition}

Images were obtained on a 64 multi-detector CT system (Toshiba Aquilion). The patient was positioned supine with arms above their head and the scan range was from above the diaphragms (lung bases) to the lesser trochanters. Images were acquired in the arterial phase after injection of $100 \mathrm{ml}$ of intravenous contrast material (Omnipaque ${ }^{\curvearrowleft}$ 300, GE healthcare). The following acquisition parameters were used: $120 \mathrm{kV}$, reference tube $182 \mathrm{mAs}$, $0.5 \mathrm{~s}$ rotation time, helical pitch 53. The slice thickness was $1 \mathrm{~mm}$ and sections were reconstructed in the axial, coronal and sagittal planes of $3 \times 3 \mathrm{~mm}$.

\section{EVIF definition}

EVIF was defined as any finding that was previously unknown to the reporting radiologist, which was not included in the scan request forms or previous CTAs. This included, for example, a known lymphoma to the clinician but not the radiologist. Scan request details were reviewed to identify any known conditions and final reports were scrutinized using the patient archiving and communication system (PACS), and any EVIF noted was included in the data collection. Only the first reported EVIF was included and any similar EVIFs in subsequent scans were excluded.

\section{EVIF classification}

EVIFs were classified according to a previous study and the White Paper of the American College of Radiology (ACR) Incidental Findings Committee 2010 based on clinical relevance, into (I) immediate, (II) potential and (III) no clinical relevance (Preuss et al. 2015; Berland et al. 2010). Immediate clinical relevance (Class I) was defined as any finding that required urgent intervention, treatment or follow-up and included any highly suspicious malignant findings 
and infective sources that may lead to severe morbidity or mortality. Class II or potential clinically relevant findings were identified if the finding may lead to future morbidity and could require follow up, for example, including small pulmonary nodules $(<1 \mathrm{~cm})$ and non-obstructing renal stones. Findings with no clinical relevance (Class III) did not require follow up or change in management, such as simple renal and hepatic cysts or degenerative lumbar spine.

\section{Data analysis}

All scans were reported by any one of six consultant vascular radiologists and retrospective review of malignant findings on surveillance CTA was undertaken by two of the same six consultant vascular radiologists with 7 and 20 years of consultant experience. Incidental malignant findings were classified into two groups; planning (if identified on the first scan) or surveillance CTA (identified on any follow up scans) and then further categorized into missed or non-visible findings following retrospective review. Clinical follow up, diagnoses and management were reviewed for significant findings and were based on electronic records of clinic letters, further imaging, histopathology and biochemistry results and drug charts. All data was computed and analysed using Microsoft Excel 2011 V14.2.

\section{Results}

In our study, a total of 950 EVIFs were noted in 2203 CT scans of 418 patients (31 females (7.4\%), 387 males (92.6\%); age range 63-93, mean age $79.0 \pm 6.6(\mathrm{SD})$ years; mean scans per patient $5.3 \pm 2.8(\mathrm{SD}))$. There were 115 patients (27.5\%) with 144 Class I findings, 165 patients (39.5\%) with 209 Class II findings and 304 patients (72.7\%) with 597 Class III findings. At least one finding was noted in 362 patients (86.6\%) and 38 patients (9.1\%) had findings in all three categories.

All findings were classified according to three anatomical areas; Chest, Abdomen, Musculoskeletal (MSK). In Class I, there were 100 (69.2\%) significant EVIFs in the abdomen, $42(29.4 \%)$ in the chest and $2(1.4 \%)$ were MSK. Of 144 Class 1 findings, follow up information was available for 115 EVIFs (79.9\%) while 29 were unknown. These findings are summarised in Table 1.

Incidental malignant findings, which accounted for the largest combined group of EVIFs in Class I, were reported in 51 patients (12.2\%) [49 males, 2 females, mean age 80.9 years], of which 27 were noted on the planning CTA and 24 on follow-up CTAs. Of the 24 patients, 13 had early malignant findings missed or misinterpreted on previous CTAs, while 11 had no significant abnormality even on retrospective review (Table 2). Retrospectively, 2 of the 13 missed malignant findings were originally identified but dismissed as benign, which included a tiny lung base lesion later diagnosed as bronchogenic lung carcinoma and pancreatic duct dilatation initially felt to be due to chronic pancreatitis, which ultimately proved to be secondary to pancreatic malignancy. There was a $100 \%$ inter-rater agreement between both radiologists in assessing the malignant findings retrospectively in surveillance CTAs.

There was a spread of 12 different malignancies identified. The highest overall frequencies of incidental malignancies were colorectal cancer (10), urinary bladder cancer (9) and lung cancer (8). The distribution of colorectal cancers included four caecal and two each in the ascending colon, sigmoid and rectum. Amongst the 27 malignant findings identified on the planning CTA, the most frequent were colorectal (7) and urinary bladder (6) cancers. Urinary bladder cancer (3) and liver metastasis (3) were the most common missed malignant findings in retrospect. The others included pancreatic cancer (1), renal cancer (1), lung cancer (1), colorectal cancer (1), prostate cancer (1), bone metastasis (1) and Non-Hodgkin's Lymphoma (1). Three lung and two colorectal cancer cases were the most frequent malignancies that could not be identified on previous scans even in retrospect. Figure 1 includes examples of subtle missed early malignant findings.

The most common Class II EVIFs included gallstones (102), small pleural effusions (24) and renal calculi (20). Class III EVIFs were most frequently identified as uncomplicated diverticulosis (147), simple renal cysts (101) and degenerative lumbar spine (68). The remaining EVIFs are summarised in Tables 3 and 4 respectively.

\section{Discussion}

A high number of significant EVIFs can be identified in follow-up CTAs of patients who undergo EVAR, which is of importance in this higher risk cohort of elderly patients with multiple co-morbidities. Many of these EVIFs were followed up and were shown to cause a change in the management of patients by aiding early diagnoses.

This study included a large sample of patients (418) and scans (2203) compared to previous studies, ranging from 82 to 290 patients (Preuss et al. 2015; Tornqvist et al. 2016; Naidu et al. 2010; Indes et al. 2008; Waqas et al. 2014; Gufler et al. 2014). The incidence of EVIFs in Class I was higher than most previous studies (range $6.5 \%-23.7 \%$ ), but lower than 37 and $42 \%$ in Tornqvist et al. and Indes et al.'s studies respectively (Katz et al. 1999; McDougal et al. 2006; Preuss et al. 2015; Tornqvist et al. 2016; Naidu et al. 2010; Indes et al. 2008; Waqas et al. 2014; Gufler et al. 2014). In our study, classification of EVIFs was similar to Preuss et al.'s study, which 
Table 1 Class I extravascular incidental findings according to system area. (MSK denotes musculoskeletal)

\begin{tabular}{|c|c|c|c|}
\hline System & Incidental findings & Number (relative Frequency \%) & Follow-up \\
\hline \multirow[t]{5}{*}{ Chest } & Lung mass/cancer & $9(6.3)$ & 8 cancers confirmed, 1 benign \\
\hline & Pericardial effusion & $2(1.4)$ & 1 treated, 1 died \\
\hline & Pleural effusion (moderate/large) & $5(3.5)$ & 3 treated, 2 unknown \\
\hline & Pneumonia & $24(16.8)$ & 6 treated, 3 asymptomatic, 15 unknown \\
\hline & Pulmonary embolus & $2(1.4)$ & 2 treated \\
\hline \multirow[t]{23}{*}{ Abdomen } & Abdominal ascites & $1(0.7)$ & Cardiac failure \\
\hline & Acute pancreatitis & $2(1.4)$ & Treated \\
\hline & Adrenal lesion (suspicious) & $1(0.7)$ & Stable \\
\hline & Appendicitis & $1(0.7)$ & Unknown \\
\hline & Bladder wall thickening/cancer & $17(11.9)$ & 9 cancers confirmed, 8 benign, 1 unknown \\
\hline & Bone metastasis & $3(2.1)$ & 3 confirmed \\
\hline & Carcinoid tumour & $1(0.7)$ & Confirmed \\
\hline & Colorectal mass/cancer & $24(16.8)$ & 10 cancers confirmed, 14 benign \\
\hline & Cholecystitis & $4(2.8)$ & 3 treated, 1 unknown \\
\hline & Colovesical fistula & $1(0.7)$ & Treated \\
\hline & Diverticulitis & $2(1.4)$ & Unknown \\
\hline & Gallbladder mass/cancer & $1(0.7)$ & Cancer confirmed \\
\hline & Gastric wall thickening/cancer & $4(2.8)$ & 2 cancers confirmed, 2 benign \\
\hline & Hydronephrosis (moderate/severe) & $11(7.4)$ & 3 stented, 1 chronic, 7 unknown \\
\hline & Liver mass/cancer & $4(2.8)$ & 3 metastasis, 1 benign \\
\hline & Pancreatic mass/cancer & $2(1.4)$ & 2 cancers confirmed \\
\hline & Prostate mass/cancer & $4(2.8)$ & 4 cancers confirmed \\
\hline & Pyelonephritis & $1(0.7)$ & Treated \\
\hline & Renal mass/cancer & $8(5.6)$ & 3 cancers confirmed, 5 benign \\
\hline & Splenomegaly & $1(0.7)$ & Known Non-Hodgkin's Lymphoma \\
\hline & Splenic lesion (suspicious) & $1(0.7)$ & Likely haemangioma, surveillance \\
\hline & Strangulated inguinal hernia & $1(0.7)$ & Unknown \\
\hline & Widespread lymphadenopathy & $5(3.5)$ & 4 Non-Hodgkin's lymphoma \\
\hline \multirow[t]{2}{*}{ MSK } & Osteomyelitis & $1(0.7)$ & Unknown \\
\hline & Pathological humeral fracture & $1(0.7)$ & Bone metastasis \\
\hline Total & & 144 & \\
\hline
\end{tabular}

explains the comparable $27 \%$ of EVIF incidence (Preuss et al. 2015). However, the lack of standardisation of EVIF definitions and differences in EVIF classification across other studies make the results less directly comparable. Difference in the scanner type (single helical CT) and inclusion of the venous phase in Katz et al.'s and Naidu et al.'s studies respectively, may have also influenced the findings (Katz et al. 1999; Naidu et al. 2010).

The marked gender imbalance $(92.6 \%$ males $)$ in the study could possibly explain the few gynaecological pathologies detected while the lack of EVIFs in the MSK region compared with other studies could be accounted for by the total area imaged that included lower limbs in other publications (Preuss et al. 2015; Naidu et al. 2010). Overall findings of high frequencies of pneumonia, gallstones, simple renal and hepatic cysts, diverticular disease and degenerative lumbar spine in each class were in line with previously reported studies (Preuss et al. 2015; Waqas et al. 2014; Iezzi et al. 2007). However, our follow-up rate (80\%) for important EVIFs was significantly better than other studies (40\% reported in Preuss et al., 58\% in Naidu et al. and 73\% in McDougal et al.) (McDougal et al. 2006; Preuss et al. 2015; Naidu et al. 2010).

Most lung consolidative changes were identified on the first post-EVAR CTA and were likely due to secondary complications of hospital admissions. Patients who were asymptomatic at the clinical follow up required no intervention. A large number of patients who underwent 
Table 2 Extravascular incidental malignant findings on planning and surveillance CT Angiogram

\begin{tabular}{lllll}
\hline Type of cancer & \multicolumn{4}{l}{ Number Relative frequency \%) } \\
\cline { 2 - 4 } & $\begin{array}{l}\text { Planning } \\
\text { CTA }\end{array}$ & \multicolumn{2}{l}{ Surveillance CTA } & Total \\
\cline { 3 - 4 } Bladder & $6(22.2)$ & 0 & $3(23)$ & $9(17.6)$ \\
Bone & $1(3.7)$ & $1(9.1)$ & $1(7.7)$ & $3(5.9)$ \\
Carcinoid & $1(3.7)$ & 0 & 0 & $1(1.9)$ \\
Colorectal & $7(25.9)$ & $2(18.2)$ & $1(7.7)$ & $10(19.6)$ \\
Gallbladder & 0 & $1(9.1)$ & 0 & $1(1.9)$ \\
Gastric & $1(3.7)$ & $1(9.1)$ & 0 & $2(3.9)$ \\
Liver & 0 & 0 & $3(23)$ & $3(5.9)$ \\
Lung & $4(14.8)$ & $3(27.2)$ & $1(7.7)$ & $8(15.7)$ \\
Non Hodgkin's Lymphoma & $3(11.1)$ & $1(9.1)$ & $1(7.7)$ & $5(9.8)$ \\
Pancreatic & 0 & $1(9.1)$ & $1(7.7)$ & $2(3.9)$ \\
Prostate & $2(7.4)$ & $1(9.1)$ & $1(7.7)$ & $4(7.8)$ \\
Renal & $2(7.4)$ & 0 & $1(7.7)$ & $3(5.9)$ \\
Total & 21 & 11 & 13 & 51 \\
\hline
\end{tabular}

further work up for suspicious lesions yielded malignant results (51 of 85). This highlights the importance of a low threshold for further investigation of patients who had Class I EVIFs diagnosed on surveillance CTAs.

In our study, there was a higher incidence of incidental malignancies (12.2\%) compared to previous studies (range 0-5.2\%) (Preuss et al. 2015; Tornqvist et al. 2016;
Naidu et al. 2010; Gufler et al. 2014; Iezzi et al. 2007; Belgrano et al. 2010; Prabhakar et al. 2015; Hughes et al. 2016; Ho et al. 2016). This could be attributed to the nature of our study, which included surveillance CTAs over an extended period and larger number of scans. It can be postulated that the greater malignant findings detected was more likely in an elderly age group with higher co-morbidities, although similar patient demographics were observed in Preuss et al., Tornqvist et al., Gufler et al., and Indes et al.'s studies (mean age 74.9, 78.7, 81.6, and 76 respectively) (Preuss et al. 2015; Tornqvist et al. 2016; Indes et al. 2008; Gufler et al. 2014). Certain malignancies were also known to clinicians at diagnosis (10 of 51) but not included in the request reports and were unknown to the reporting radiologists. However, this was still relevant and included as it remained a new diagnosis to the radiologist.

The high frequency of urinary bladder cancer in the cohort was an intriguing observation while the high number of colorectal cancers was unsurprising.

A possible explanation for the commonly missed liver malignancy could be the limitation of an arterial phase scan in detecting and characterising liver lesions. Some missed early malignant findings were also very subtle in retrospect and could be easily overlooked or dismissed as a benign finding at the time of reporting. However, it is difficult to draw conclusions due to the small number of cases. All retrospectively missed incidental malignant findings were discussed at the departmental discrepancy meeting and any unexpected findings were escalated in

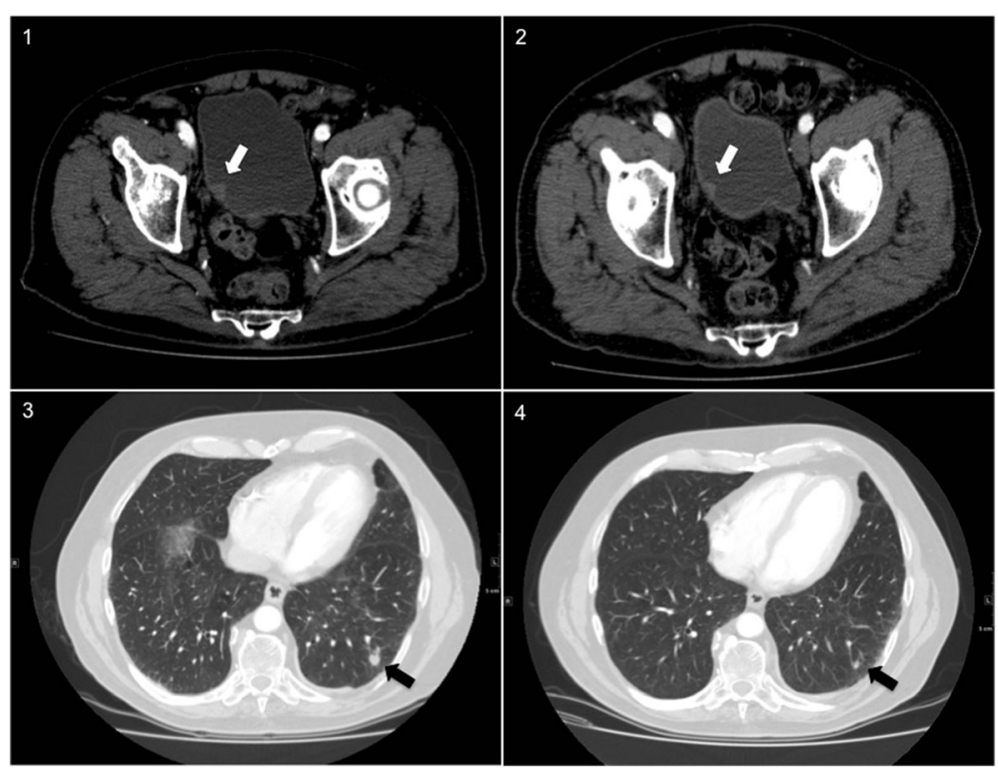

Fig. 1 Example images of missed malignant findings on surveillance CT Angiogram post endovascular aortic aneurysm repair. Axial slice of CTA showing the urinary bladder right lateral wall thickening (white arrow), confirmed bladder transitional cell carcinoma at diagnosis (1) and retrospectively on a previous scan (2). Axial slice of CTA showing the $11 \mathrm{~mm}$ left lung lower lobe lesion (black arrow), confirmed adenosquamous lung cancer at diagnosis (3) and retrospectively on a previous scan (4), which was initially considered benign 
Table 3 Class II extravascular incidental findings according to system area. (MSK denotes musculoskeletal)

\begin{tabular}{|c|c|c|c|}
\hline System & Incidental findings & $\begin{array}{l}\text { Number (relative } \\
\text { frequency \%) }\end{array}$ & Follow-up \\
\hline \multirow[t]{6}{*}{ Chest } & Cardiomegaly & $3(1.4)$ & \\
\hline & $\begin{array}{l}\text { Coronary artery } \\
\text { calcification }\end{array}$ & $1(0.5)$ & \\
\hline & Pleural effusion (small) & $24(11.4)$ & \\
\hline & Pleural nodule $(<1 \mathrm{~cm})$ & $2(1.0)$ & 2 benign \\
\hline & $\begin{array}{l}\text { Pulmonary nodules } \\
(<1 \mathrm{~cm})\end{array}$ & $3(1.4)$ & 3 no growth \\
\hline & Rib fracture & $1(0.5)$ & $\begin{array}{l}\text { No } \\
\text { intervention }\end{array}$ \\
\hline \multirow[t]{16}{*}{ Abdomen } & Appendix mucocoele & $1(0.5)$ & \\
\hline & Bladder calculi & $3(1.4)$ & \\
\hline & Chronic pancreatitis & $1(0.5)$ & \\
\hline & $\begin{array}{l}\text { Dilated common bile } \\
\text { duct }\end{array}$ & $8(3.8)$ & $\begin{array}{l}6 \text { no cause, } \\
2 \text { gallstones }\end{array}$ \\
\hline & Gallstones & $102(48.5)$ & \\
\hline & Hydrocoele & $1(0.5)$ & No change \\
\hline & Hydronephrosis (mild) & $3(1.4)$ & \\
\hline & $\begin{array}{l}\text { Incarcerated hiatus } \\
\text { hernia }\end{array}$ & $2(1.0)$ & $\begin{array}{l}2 \text { no } \\
\text { intervention }\end{array}$ \\
\hline & $\begin{array}{l}\text { Lymphadenopathy } \\
\text { (coeliac/mediastinal) }\end{array}$ & $5(2.3)$ & \\
\hline & $\begin{array}{l}\text { Meningocoele (S2 neural } \\
\text { foramina) }\end{array}$ & $1(0.5)$ & $\begin{array}{l}\text { No } \\
\text { intervention }\end{array}$ \\
\hline & Ovarian dermoid & $1(0.5)$ & \\
\hline & $\begin{array}{l}\text { Pancreatic duct } \\
\text { dilatation }\end{array}$ & $1(0.5)$ & $\begin{array}{l}\text { No } \\
\text { intervention }\end{array}$ \\
\hline & Pancreatic pseudocyst & $8(3.8)$ & $\begin{array}{l}8 \text { no } \\
\text { intervention }\end{array}$ \\
\hline & Prostate hypertrophy & $10(4.7)$ & \\
\hline & Renal stone & $20(9.5)$ & \\
\hline & Uterine fibroids & $1(0.5)$ & \\
\hline \multirow[t]{4}{*}{ MSK } & Hip osteoarthritis & $2(1.0)$ & \\
\hline & L5/S1 spondylolisthesis & $3(1.4)$ & \\
\hline & Paget's of hemipelvis & $1(0.5)$ & \\
\hline & Sacral sclerotic change & $1(0.5)$ & $\begin{array}{l}\text { No } \\
\text { intervention }\end{array}$ \\
\hline \multicolumn{2}{|l|}{ Total } & 209 & \\
\hline
\end{tabular}

accordance with the Royal College of Radiologists (RCR) and General Medical Council (GMC) Duty of Candour statements (The professional duty of candour 2015).

A limitation of our study included a possible underestimation of EVIFs as only the final scan reports were reviewed. However, as the surveillance scans were reported by experienced consultant radiologists and any previous scans were compared during reporting, the number of undetected EVIFs should be limited in
Table 4 Class III extravascular incidental findings according to system area. (MSK denotes musculoskeletal)

\begin{tabular}{|c|c|c|}
\hline System & Incidental findings & $\begin{array}{l}\text { Number (relative } \\
\text { frequency \%) }\end{array}$ \\
\hline \multirow[t]{6}{*}{ Chest } & Bronchiectasis & $16(2.7)$ \\
\hline & Diaphragmatic hernia & $3(0.5)$ \\
\hline & Emphysema & $58(9.7)$ \\
\hline & Lung fibrosis & $31(5.2)$ \\
\hline & Pleural plaque & $25(4.2)$ \\
\hline & Pulmonary atelectasis & $14(2.3)$ \\
\hline \multirow[t]{19}{*}{ Abdomen } & Abdominal wall hernia & $4(0.6)$ \\
\hline & Adrenal adenoma & $10(1.6)$ \\
\hline & Diverticular disease & $147(24.6)$ \\
\hline & Epigastric hernia & $1(0.2)$ \\
\hline & Hiatus hernia & $18(3)$ \\
\hline & Horseshoe kidney & $1(0.2)$ \\
\hline & Incisional hernia & $1(0.2)$ \\
\hline & Inguinal hernia & $21(3.5)$ \\
\hline & Inguinal lymphocoele & $1(0.2)$ \\
\hline & Liver haemangioma & $1(0.2)$ \\
\hline & Lymphocoele & $1(0.2)$ \\
\hline & Mesenteric panniculitis & $2(0.3)$ \\
\hline & Ovarian cyst & $1(0.2)$ \\
\hline & Pancreatic calcification & $2(0.3)$ \\
\hline & Parastomal hernia & $1(0.2)$ \\
\hline & Simple liver cyst & $56(9.4)$ \\
\hline & Simple renal cyst & $101(16.9)$ \\
\hline & Spigelian hernia & $1(0.2)$ \\
\hline & Splenunculi & $1(0.2)$ \\
\hline \multirow[t]{4}{*}{ MSK } & Degenerative lumbar spine & $68(11.4)$ \\
\hline & Lumbar wedge fracture & $4(0.6)$ \\
\hline & Thoracic wedge fracture & $6(1.0)$ \\
\hline & Vertebral body haemangioma & $1(0.2)$ \\
\hline Total & & 597 \\
\hline
\end{tabular}

number. Follow up data did not include paper medical records, which accounted for the incomplete clinical follow up rates. A few patients had also died prior to a full work up or follow up. While an interesting aspect of our study included the retrospective review of incidental malignancies on surveillance CTA, our results may have been biased by the reviewing radiologists having prior knowledge of the clinical diagnosis.

\section{Conclusion}

A significant amount of EVIFs, particularly incidental malignancies, can be detected in surveillance CTAs of patients post-EVAR. Hence, it is prudent to be vigilant in 
evaluation of abdominal CTAs and necessary clinical follow-up arranged. Comprehensive overview of checklist areas with particular attention to the liver and bladder, which were commonly missed sites for early pathology, can be suggested on the basis of our findings. It remains to be seen if change in patients' management following important EVIF detection and arguably earlier diagnoses, significantly translates into improved patient outcome. Future work may include the cost analysis and radiation exposure of follow up imaging and potential procedures.

\section{Abbreviations}

AAA: Abdominal Aortic Aneurysm; CT: Computed Tomography; CTA: Computed Tomography Angiography; EVAR: Endovascular Aortic Repair; EVIF: Extravascular Incidental Finding; GMC: General Medical Council; MSK: Musculoskeletal; RCR: Royal College of Radiologists

\section{Availability of data and materials}

Please contact authors for data requests.

\section{Authors' contributions}

PSD - Study concept and design, Literature search, Data collection/ analysis, Manuscript preparation/editing; MWB - Study concept and design, Literature search, Data collection/analysis, Manuscript preparation/editing; GP - Data collection/analysis, Manuscript preparation/editing; JK - Data collection/analysis, Manuscript preparation/ editing; PB - Data collection/analysis, Manuscript preparation/editing; MDN - Study concept and design, Data collection/analysis, Manuscript preparation/editing; PT - Study concept and design, Data collection/ analysis, Manuscript preparation/editing. All authors read and approved the final manuscript.

\section{Ethics approval and consent to participate}

No IRB approval or consent was required for this retrospective review.

\section{Consent for publication}

Not Applicable.

\section{Competing interests}

The authors declare that they have no competing interests.

\section{Publisher's Note}

Springer Nature remains neutral with regard to jurisdictional claims in published maps and institutional affiliations.

\section{Author details}

${ }^{1}$ Clinical Radiology, Royal Derby Hospital, Derby Teaching Hospitals NHS Foundation Trust, Derby, UK. ${ }^{2}$ Radiological Sciences, University of Nottingham, Queen's Medical Centre, Nottingham, UK. ${ }^{3}$ Clinical Radiology, Queens Medical Centre, Nottingham University Hospitals NHS Trust, Nottingham NG7 2UH, UK.

Received: 2 January 2018 Accepted: 28 March 2018

Published online: 04 September 2018

\section{References}

Belgrano $\mathrm{M}$ et al (2010) Prevalence of extravascular collateral findings during 64-slice CT angiography of the abdominal aorta and lower limbs. Radiol Med 115(6):983-996

Berland LL et al (2010) Managing incidental findings on abdominal CT: white paper of the ACR incidental findings committee. J Am Coll Radiol 7(10): 754-773

Chaer RA et al (2009) Duplex ultrasound as the sole long-term surveillance method post-endovascular aneurysm repair: a safe alternative for stable aneurysms. J Vasc Surg 49(4):845-849 Discussion 849-50
De Bruin $J$ et al (2010) Long-term outcome of open or endovascular repair of abdominal aortic aneurysm. N Engl J Med 362(20):1881-1889

Dua A et al (2014) Epidemiology of aortic aneurysm repair in the United States from 2000 to 2010. J Vasc Surg 59(6):1512-1517

Greenhalgh RM et al (2004) Comparison of endovascular aneurysm repair with open repair in patients with abdominal aortic aneurysm (EVAR trial 1), 30-day operative mortality results: randomised controlled trial. Lancet 364(9437):843-848

Gufler H, Schulze CG, Wagner S (2014) Incidental findings in computed tomographic angiography for planning percutaneous aortic valve replacement: advanced age, increased cancer prevalence? Acta Radiol 55(4):420-426

Hirsch AT et al (2006) ACC/AHA 2005 practice guidelines for the management of patients with peripheral arterial disease (lower extremity, renal, mesenteric, and abdominal aortic): a collaborative report from the American Association for Vascular Surgery/Society for Vascular Surgery, Society for Cardiovascular Angiography and Interventions, Society for Vascular Medicine and Biology, Society of Interventional Radiology, and the ACC/AHA task force on practice guidelines (writing committee to develop guidelines for the Management of Patients with Peripheral Arterial Disease): endorsed by the American Association of Cardiovascular and Pulmonary Rehabilitation; National Heart, Lung, and Blood Institute; Society for Vascular Nursing; TransAtlantic inter-society consensus; and vascular disease foundation. Circulation 113(11):e463-e654

Ho OA et al (2016) Incidentalomas associated with abdominal and pelvic CT angiograms for abdominal-based breast free flap reconstruction. J Plast Reconstr Aesthet Surg 69(5):e97-e102

Hobo R, Buth J, EUROSTAR collaborators (2006) Secondary interventions following endovascular abdominal aortic aneurysm repair using current endografts. A EUROSTAR report. J Vasc Surg 43(5):896-902

Hoornweg LL et al (2007) The Amsterdam acute aneurysm trial: suitability and application rate for endovascular repair of ruptured abdominal aortic aneurysms. Eur J Vasc Endovasc Surg 33(6):679-683

Hughes JM et al (2016) Incidental findings in CT angiograms for free DIEP flap breast reconstruction - do they change our management? Eur J Surg Oncol 42(1):59-63

lezzi R et al (2006) Multidetector CT in abdominal aortic aneurysm treated with endovascular repair: are unenhanced and delayed phase enhanced images effective for endoleak detection? Radiology 241(3):915-921

lezzi R et al (2007) Extravascular incidental findings at multislice $C T$ angiography of the abdominal aorta and lower extremity arteries: a retrospective review study. Abdom Imaging 32(4):489-494

Indes JE et al (2008) Incidence and significance of nonaneurysmal-related computed tomography scan findings in patients undergoing endovascular aortic aneurysm repair. J Vasc Surg 48(2):286-290

Katz DS, Jorgensen MJ, Rubin GD (1999) Detection and follow-up of important extra-arterial lesions with helical CT angiography. Clin Radiol 54(5):294-300

Lederle FA et al (2009) Outcomes following endovascular vs open repair of abdominal aortic aneurysm: a randomized trial. JAMA 302(14):1535-1542

Macari M et al (2006) Abdominal aortic aneurysm: can the arterial phase at CT evaluation after endovascular repair be eliminated to reduce radiation dose? Radiology 241(3):908-914

McDougal $J$ et al (2006) Computed tomographic angiography has added value in patients with vascular disease. J Vasc Surg 44(5):998-1001

Naidu SG et al (2010) Incidence of highly important extravascular findings detected on CT angiography of the abdominal aorta and the lower extremities. AJR Am J Roentgenol 194(6):1630-1634

Prabhakar AM et al (2015) Incidental findings and recommendations are common on ED CT angiography to evaluate for aortic dissection. Am J Emerg Med 33(11):1639-1641

Preuss A et al (2015) Extravascular incidental findings in run-off CT angiography in patients with acute limb ischaemia: incidence and clinical relevance. Clin Radiol 70(6):622-629

Sternbergh WC 3rd et al (2008) Redefining postoperative surveillance after endovascular aneurysm repair: recommendations based on 5-year followup in the US Zenith multicenter trial. J Vasc Surg 48(2):278-284 Discussion 284-5

The professional duty of candour (2015) Available from: http://www.gmc-uk.org/ DoC_guidance_englsih.pdf_61618688.pdf. Accessed on 31 May 2016 
Tornqvist P et al (2016) Postoperative $C T$ evaluation after EVAR: a comparison of image assessment. J Endovasc Ther 23(1):125-129

Trial I et al (2009) The immediate Management of the Patient with rupture: open versus endovascular repair (IMPROVE) aneurysm trial-ISRCTN 48334791 IMPROVE trialists. Acta Chir Belg 109(6):678-680

Walker TG et al (2010) Clinical practice guidelines for endovascular abdominal aortic aneurysm repair: written by the standards of practice Committee for the Society of interventional radiology and endorsed by the cardiovascular and interventional radiological Society of Europe and the Canadian interventional radiology association. J Vasc Interv Radiol 21(11):1632-1655

Waqas S et al (2014) Incidental findings detected on abdomino-pelvic multidetector computed tomography performed in the acute setting. Am 」 Emerg Med 32(1):36-39

\section{Submit your manuscript to a SpringerOpen ${ }^{\bullet}$ journal and benefit from:}

- Convenient online submission

- Rigorous peer review

- Open access: articles freely available online

- High visibility within the field

- Retaining the copyright to your article

Submit your next manuscript at $\gg$ springeropen.com 